\title{
STUDYING THE EFFECTS OF VELOCITY AND COEFFICIENT OF FRICTION IN WATER HAMMER CALCULATIONS
}

\author{
A M Abdul Razzak \\ M.Sc. Building and Construction Engineering/Water Resources, \\ Surveying Department, Engineering College, \\ Baghdad university- Iraq \\ Rafah Zuhair Al-Shaikh \\ M.Sc. Water Resources Engineering, \\ Center of Urban and Regional Planning, \\ Baghdad University-Iraq
}

\begin{abstract}
A system of tank and pipe with valve was studied by the computer program that was prepared to calculate water hammer equations in a previous published paper by the first researcher.

Almost 50 table of results gained after running the program with different values of velocities and coefficient of friction. The values of head, was studied very well to get several notes about this noisy phenomenon.
\end{abstract}

- Generally, the curve layout for the results of the water hammer is almost constant, except for a slight difference.

- With the stability of the speed and the change of coefficient friction, we found that the results of the head at one point for example, in the middle of the distance between the tank and the valve, are variable and decrease with the high coefficient of friction.

- Values of time in the tables will be decrease when increasing of velocity, nearly between 91$93 \%$.

- The values of head after running the program, when the valve is initially closed for any speed with constant coefficient of friction is almost constant despite the change of speed and to certain limits, changes in head values start within the limits of the seventh and eighth points of time values and the head values are lower for the higher speed.

\section{Symbols:}

$A=$ cross-sectional pipe area

$a=$ liquid wave speed

$A_{O}=$ cross-sectional orifice area

$P=$ pressure

Re $=$ Reynolds number

$\theta=$ pipe slope

$C_{d}=$ orifice discharge coefficient

$C_{P}, C_{M}=$ known variable coefficient

$C V=$ Product of discharge coefficient

$\beta=$ momentum correction factor

$\rho=$ mass density of fluid

$e=$ pipe-wall thickness

$E, E_{0}=$ Young's modulus of elasticity of pipe

$f=$ Darcy-Weisbach friction factor

$g=$ gravitational acceleration

$h_{f}=$ frictional head loss per unit length

$h_{v}=$ gauge vapor pressure

$H=\mathrm{Head}$ 
$Q=$ discharge (flow) or node downstream-end discharge

Keywords: water hammer, program, tables of analysis, velocity, coefficient of friction.

Cite this Article: A M Abdul Razzak and Rafah Zuhair Al-Shaikh, Studying the Effects of Velocity and Coefficient of Friction in Water Hammer Calculations. International Journal of Civil Engineering and Technology (IJCIET), 11(1), 2020, pp.32-42.

https://iaeme.com/Home/issue/IJCIET?Volume=11\&Issue=1

\section{INTRODUCTION}

Several studies were implemented to study this noisy and difficult Phenomenon, the analysis of it assumes that it is an elastic phenomenon and the equations required are conservation equations including conservation of mass (continuity) and conservation of momentum or conservation of energy and the relation called the Equation of state which expresses the statistical stress condition of the body.

Water hammer needs to arrester to prevent hear any noisy voices occur when a valve closed abruptly or pump stoppage, the sudden rise in pressure is called HAMMER BLOW and the noisy which pressure create is known as KNOCKING.

The magnitude of pressure rise and fall depend upon: -

1. The speed at which the valve is closed.

2. The length of pipeline.

3. The elastic properties of the pipe materials.

4. The elastic properties of the flowing fluid.

The review of literature in the blow information would give us more about this phenomenon and what is its effects in small and big size pipes.

Our research deals with studies about the effects of velocity \& coefficient of friction in water hammer calculations by using a computer program that had been prepared in previous research by the first researcher and published in the international journal of civil engineering and technology (IJCIET) ${ }^{[1]}$.

Water hammer is a noisy and difficult phenomenon that occur in pipes (small size and big size but it would be evident in the big size pipe more than the small). The program calculates transients in a single pipeline with a reservoir up stream and a valve downstream figure (1).

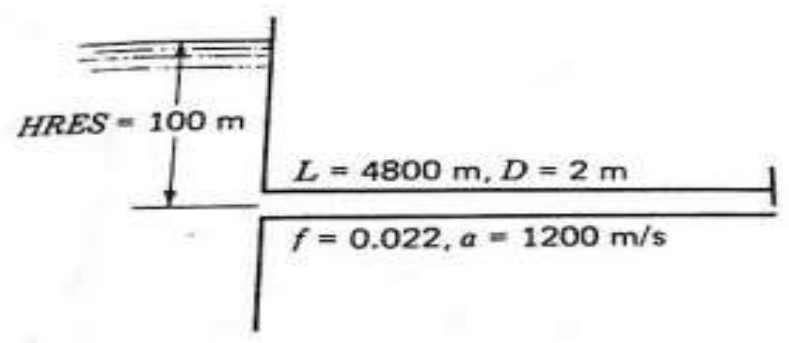

Figure.1 System for basic water hammer program.

During the start-up of the propulsion system of a spacecraft, the filling of an evacuated pipeline, a process known as priming, can generate severe pressure peaks due to the slam (water hammer) of the propellant against a closed thruster valve. For safety reasons, the propellant feedlines of a satellite or spacecraft engine are evacuated or filled with a small amount of inert gas prior to the launch. Once in orbit, the tank isolation valve opens (usually a 
pyrotechnic valve) and the evacuated lines are filled with the propellant. When the liquid propellant impacts the closed thruster valve or other dead-ends, it can create pressure peaks as high as 250 bar that may lead to structural failure if not properly taken into account in the pipeline and sub-system dimensioning. In the case of hydrazine or a mono-propellant in general, another potential risk must be considered: the rapid compression of inert gas or propellant vapor generates heat and may cause adiabatic compression detonation. A pressure surge in hydrazine cannot exceed 172 bar $(2500 \mathrm{psi})$ due to the risk of adiabatic detonation ${ }^{[2]}$.

Water hammer equations are applied for calculation of the liquid unsteady pipe flow. The assumptions in the development of the water hammer equations are ${ }^{[3]}$ :

(1) Flow in the pipeline is considered to be one-dimensional with the velocity averaged and the pressure uniform at a section.

(2) Unsteady friction losses are approximated as quasi-steady state losses.

(3) The pipe is full and remains full during the transient.

(4) There is no column separation during the transient event, i.e. the pressure is greater than the liquid vapor pressure.

(5) Free gas content of the liquid is small such that the wave speed can be regarded as a constant.

(6) The pipe wall and the liquid behave linearly elastically.

(7) Structure-induced pressure changes are small compared to the water hammer pressure wave in the liquid.

Large pipe systems with long pipelines transporting fluids over great distances is a reality in modern society. The usage of small pipe diameters, high-velocity together with sophisticated fluid control devices, many types of pumps and valves, coupled with electronic sensors have increased the importance of correct design ${ }^{[4]}$. The unsteady friction effects occurring at water hammer transients is ongoing research. Several methods have been proposed and validated by experiments. Besides unsteady friction (UF), there are three different items which may affect the classical water hammer results: viscoelasticity (VE), column separation (CS) and fluid structure interaction (FSI). Combinations of two or more items in analysis have been studied but not all different existing combinations ${ }^{[4]}$.

The Basic Differential Equation of Water hammer: Two basic mechanics equation are applied to a short segment of fluid in a pipe to obtain the differential equations for transient flow: Newton 'second law of motion and continuity equation. The dependent variables are pressure(p) and the average velocity(v)at across-section. The dependent variables are distance ( $\mathrm{x})$ along the pipe measured from the upstream and time $(\mathrm{t})$; hence $\mathrm{p}=\left(\mathrm{p}(\mathrm{x}, \mathrm{t}), \& \mathrm{v}=\mathrm{v}(\mathrm{x}, \mathrm{t})^{[5]}\right.$.

\section{Continuity Equation}

Is obtain by applying the law of conservation of mass to a flow segment, that is: -

$$
\frac{\partial p}{\partial t}+v \frac{\partial p}{\partial t}+\rho c x^{2} \frac{\partial v}{\partial x}=0
$$

\section{Momentum Equation (Equation of Motion)}

Is obtained by applying the law of conservation of momentum to a flow segment that is:

$$
\frac{\partial v}{\partial t}+v \frac{\partial v}{\partial x}+\frac{1}{\rho} \cdot \frac{\partial p}{\partial x}+g \sin \theta+f \frac{v|v|}{2 d}=0
$$

Where $\theta=$ slope angle of the pipe.

$f=$ friction factor (assume is the same as in steady flow)

In most engineering applications, the convection terms, $v \frac{\partial p}{\partial t}$ 
and $v \frac{\partial v}{\partial x}$ is very small and compared to another terms, the slop term $(g \sin \theta)$ is usually small and it can be neglected there for Eq. $1 \& 2$ can be written as:

$$
\begin{aligned}
& \frac{\partial p}{\partial t}+\rho c x^{2} \frac{\partial v}{\partial x}=0 \\
& \frac{\partial v}{\partial t}+\frac{1}{\rho} \cdot \frac{\partial p}{\partial x}+f \frac{v|v|}{2 d}=0
\end{aligned}
$$

Eq. $3 \& 4$ can only be solved antically if certain simplifying assumptions are made, such as the neglect of certain terms and for simple boundary conditions such as reservoir and valves, some method neglect friction losses which can lead to serious and errors in the calculation of pressure transients. These are some of the solving methods:

- Characteristic method.

- Finite -difference method.

- Finite- element method.

- Allievi method.

- Schneider- Bergeron graphical method.

Numerical results from the "reference model" (steady friction) and the unsteady friction model (pure convolution- based model ${ }^{[6]}$ and convolution -based model with momentum correction factor $\beta_{0}=1.019^{[7]}$ are compared with the measured results from the experimental run with the identical system parameters to the numerical model. The Reynolds number of the initial flow is 4,369 making the initial flow- state turbulent.

The smooth- pipe turbulent Vardy-Brown weighting function formulate are used ${ }^{[8]}$. The results are compared at the valve and at the midpoint in copper pipeline and are presented in(fig.2).
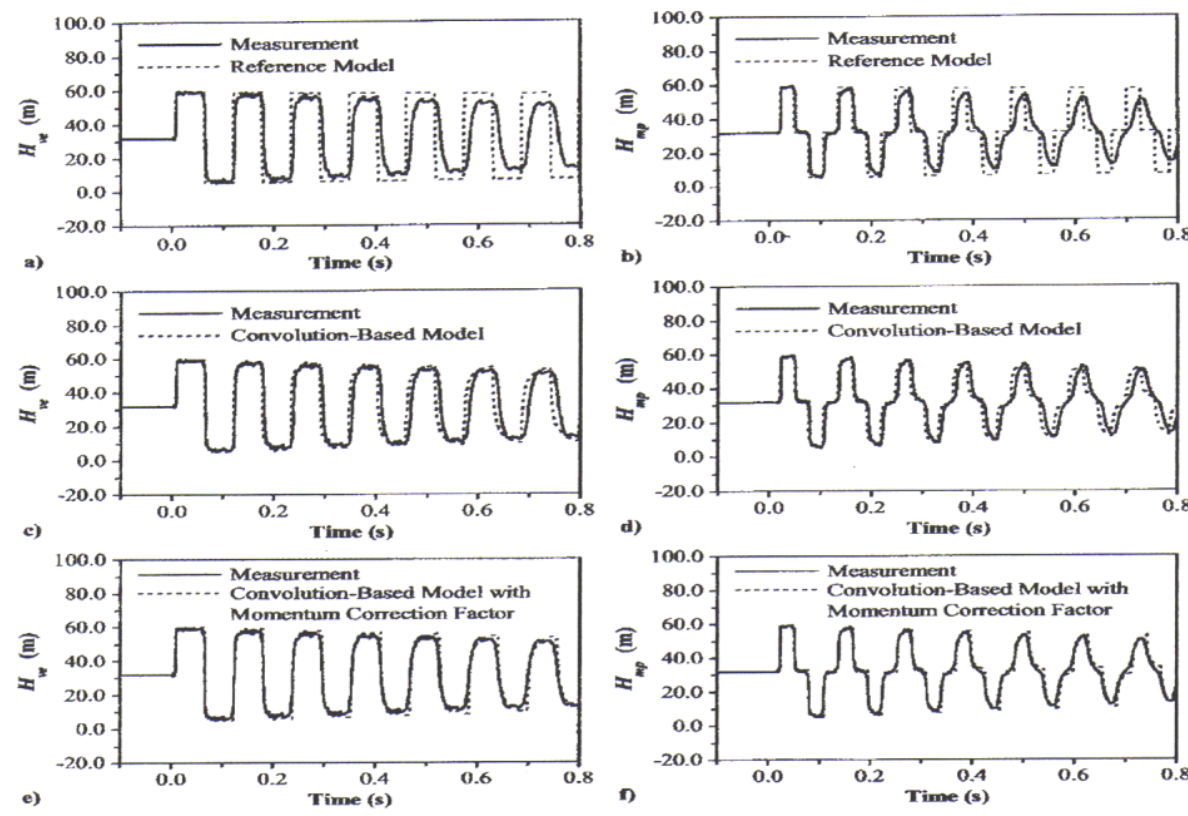

Figure 2 Comparison of heads at the valve and at the midpoint in copper pipeline.

The simulation results shown that the steady friction model underestimates the damping observed in the experimental results. Additionally, the steady friction model dose not predict the evolution of the shape of the pressure oscillation, demonstrating steady friction's inability to the model frequency-dependent attenuation. The convolution-based model better predicts 
both the shape and damping of the pressure oscillations, but becomes increasingly out - of phase with the experimental data. Finally, the convolution -based unsteady friction model including momentum correction factor performs the best closely matching frequencydependent damping and the phase of the pressure oscillations there remain some small differences between the model results and the experimental data mainly with respect to the high frequency component of the response, the simulation produce an overly sharp response whereas the experimental data are more rounded. This difference points towards a high frequency damping phenomena that is not being adequately modeled currently.

\section{THEORY OF WATER HAMMER IN THIS PAPER}

The theories of water hammer, that were used to prepared the program in reference [1] is the main. Differential equations for calculation of water hammer are two basic mechanical equation managed by applied to a short segment of fluid in a pipe ${ }^{[9]}$. These equations are, equation of motion (momentum equation) and the continuity equation which are explained above in the introduction (see fig. $2 \& 3$ ).

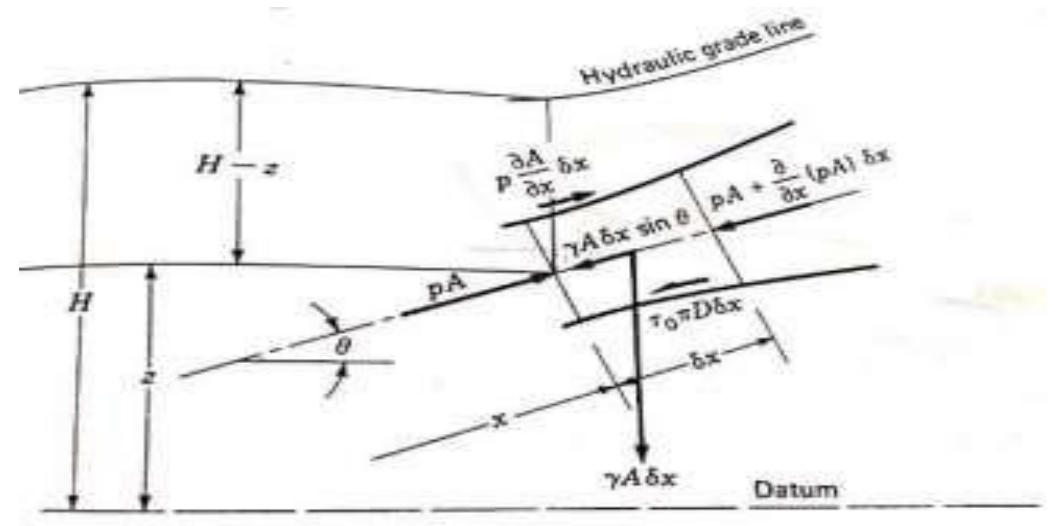

Figure 2 free body diagram for derivation

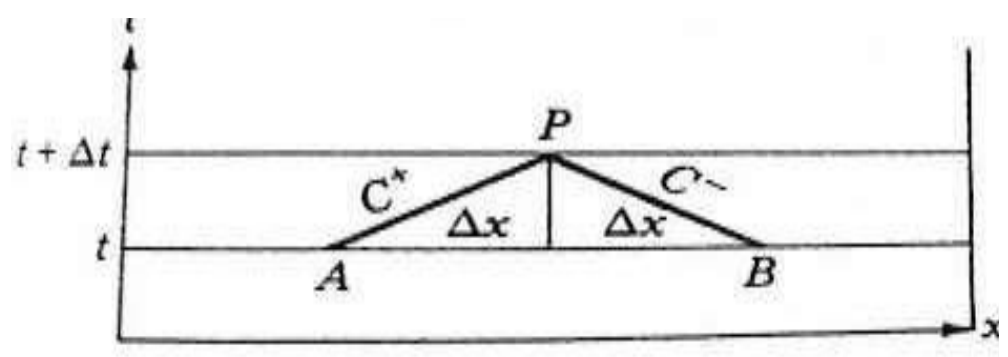

Figure 3 XT plot of characteristics along which solution is obtained

The developed program to Visual Basic from FORTRAN IV is used here. Several studies had been implemented in this research concerning velocities and coefficient of friction. Table (1) illustrate the checked data that were present after running the program and the difference between results in the original program to the same case illustrated in fig. 1 .

Table 1 Part of results gained after running program

\begin{tabular}{ccccccc}
\hline $\mathbf{X} / \mathbf{L}=\mathbf{1 . 0}$ & $\mathbf{X} / \mathbf{L}=\mathbf{. 7 5}$ & $\mathbf{X} / \mathbf{L}=. \mathbf{5 0}$ & $\mathbf{X} / \mathbf{L}=. \mathbf{2 5}$ & $\mathbf{X} / \mathbf{L}=. \mathbf{0}$ & $\mathbf{C V}$ & Time \\
\hline 98.11049 & 98.58286 & 99.05524 & 99.52762 & 100 & 0.06 & 0 \\
2.631769 & 2.631769 & 2.631769 & 2.631769 & 2.631769 & & \\
105.1225 & 98.58287 & 99.05524 & 99.52762 & 100 & 0.054 & 1 \\
2.451774 & 2.631769 & 2.631769 & 2.631769 & 2.631769 & & \\
\hline
\end{tabular}


A M Abdul Razzak and Rafah Zuhair Al-Shaikh

\begin{tabular}{ccccccc}
\hline 112.7204 & 105.5637 & 99.05524 & 99.52762 & 100 & 0.048 & 2 \\
2.256739 & 2.452575 & 2.631769 & 2.631769 & 2.631769 & & \\
120.9976 & 113.1303 & 106.005 & 99.52762 & 100 & 0.042 & 3 \\
2.045863 & 2.258344 & 2.453372 & 2.631769 & 2.631769 & & \\
129.9607 & 121.3764 & 113.5404 & 106.4464 & 100 & 0.036 & 4 \\
1.817387 & 2.048259 & 2.259942 & 2.454167 & 2.631769 & & \\
139.711 & 130.3093 & 121.7555 & 113.9508 & 100 & 0.03 & 5 \\
1.570274 & 1.820552 & 2.050646 & 2.261534 & 2.278146 & & \\
146.6829 & 140.0308 & 130.6583 & 115.2755 & 100 & 0.026 & 6 \\
1.394447 & 1.574166 & 1.823707 & 1.876945 & 1.894472 & & \\
154.0763 & 146.9848 & 133.5152 & 116.6985 & 100 & 0.022 & 7 \\
1.209287 & 1.398791 & 1.402575 & 1.459545 & 1.478663 & & \\
161.8401 & 147.5435 & 133.0191 & 118.2322 & 100 & 0.018 & 8 \\
1.014038 & 1.039032 & 1.036874 & 1.006824 & 1.027173 & & \\
157.6248 & 147.8728 & 132.2627 & 116.3213 & 100 & 0.014 & 9 \\
0.778358 & 0.653706 & 0.644893 & 0.606367 & 0.537039 & & \\
152.0384 & 142.3506 & 131.177 & 114.0349 & 100 & 0.01 & 10 \\
0.546029 & 0.385214 & 0.224385 & 0.176265 & 0.186764 & & \\
139.8051 & 135.3511 & 124.1267 & 114.8562 & 100 & 0.0086 & 11 \\
0.450297 & 0.11715 & -0.08284 & -0.19465 & -0.18406 & &
\end{tabular}

About 50 tables, like table (1) were prepared with different data of velocity and different data of coefficient of friction, (tables implemented by Microsoft Excel worksheet), and the results were discussed very well to see the influences of changing velocity. Figure (4) illustrate the program interface and it shows the information that will be entered for the program before running to get the data gained in table. 1 .

In figure. 1 , we see the values of velocity $a=1200 \mathrm{~m} / \mathrm{s}$, coefficient of friction $f=.022$, the length of pipe $\mathrm{L}=4800 \mathrm{~m}$ and diameter $=2 \mathrm{~m}$.

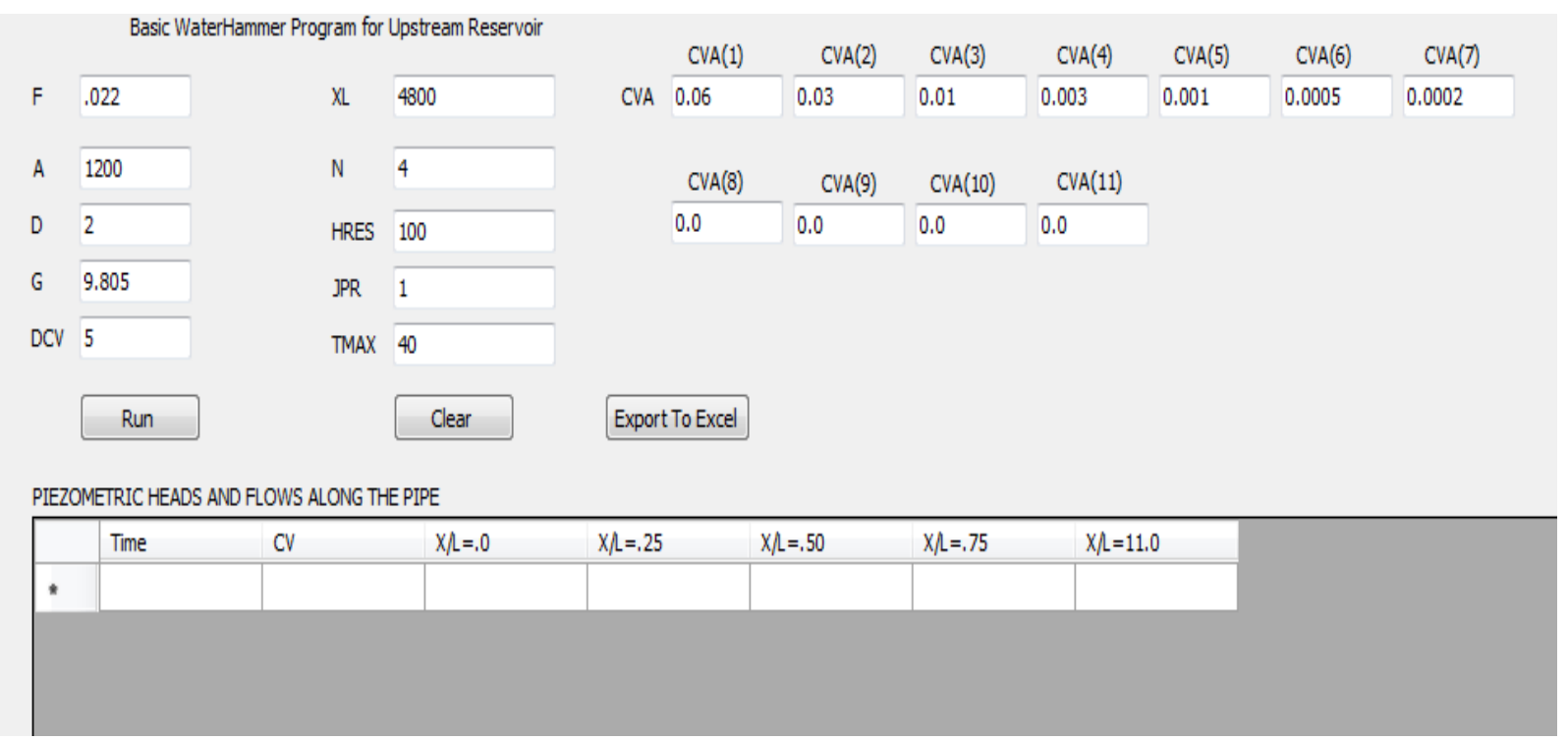

Figure 4 Data were entered to the program to get the same result in the original system [1]

If we touch the bottom run in fig.4, the results will be appearing as a table see fig.5, then we export the data to Excel as we saw it in table.1. After changing the data of velocity and coefficient of friction in fig. 1 and run the program we get the date appear in fig.6. The values of velocity changes as below with different values of coefficient of friction.

$\begin{array}{lllllllllll}\mathrm{a}=1200 & \mathrm{f}=.022 & .025 & .028 & .031 & .034 & .037 & .043 & .052 & .061 & .07\end{array}$ 
Studying the Effects of Velocity and Coefficient of Friction in Water Hammer Calculations

$\mathrm{a}=1300 \quad$ the same values of (f) as above.

$\mathrm{a}=1400 \quad$ the same values of (f) as above.

$a=1500 \quad$ the same values of (f) as above.

$\mathrm{a}=1600 \quad$ the same values of (f) as above.

For all of these data (50 cases), tables were prepared and studied, and the figures 7 to10 illustrate the curves of some results that had been gained in the tables at a distance of $\mathrm{X} / \mathrm{L}=.5$ from the upstream.

The equations that were used in the program, briefly:

$$
\begin{aligned}
& L=\frac{d V}{d t} \pm \frac{1}{\rho a} \frac{d p}{d t}+g \sin \theta+f \frac{v|v|}{2 d}=0 \\
& B=\frac{a}{g A} \quad R=\frac{\Delta_{x} f}{2 d g A^{2}} \\
& H_{p_{i}}=1 / 2\left(C_{P}+C_{M}\right) \quad \& \quad Q_{p_{i}}=\frac{C_{P}-H_{p_{i}}}{B}
\end{aligned}
$$

\subsection{Valve at Downstream End}

For steady-state flow through the valve $Q_{0}=\left(C_{d} A_{v}\right)_{0} \sqrt{2 g H_{0}}$ With $\mathrm{Q}_{0}$ the steady-state flow, $\mathrm{H}_{0}$ the head across the valve, and $\left(C_{d} A_{v}\right)_{0}$ the area of the opening times the discharge coefficient. For another opening, in general,

$$
Q_{p}=C_{d} A_{v} \sqrt{2 g H_{p}}
$$

The solution of Equations;

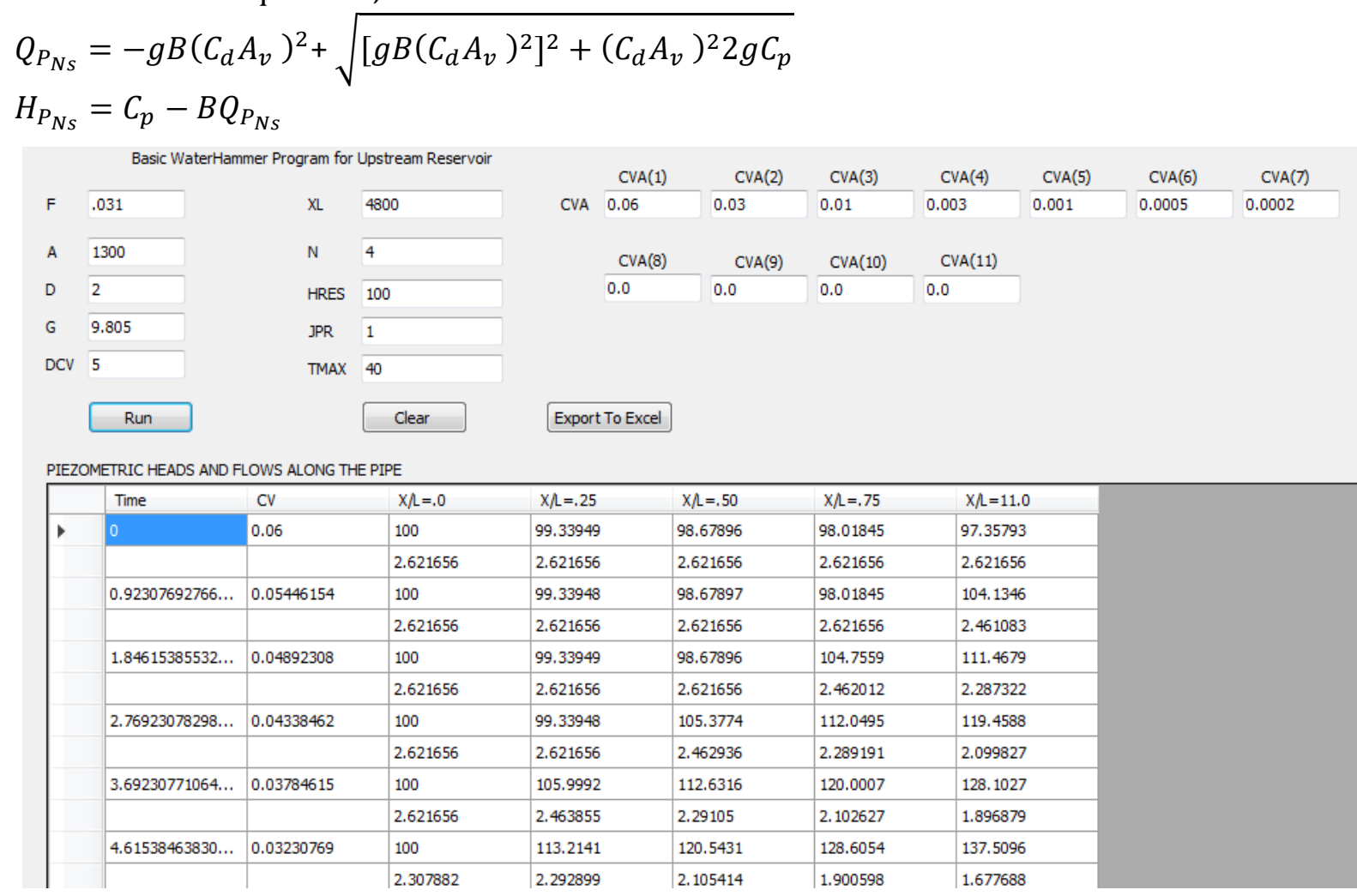

Figure 5 results after running the program with velocity of $1200 \mathrm{~m} / \mathrm{s}$ and $\mathrm{f}=.022$ (see fig.7) 


\begin{tabular}{|c|c|c|c|c|c|c|c|c|c|c|}
\hline \multicolumn{4}{|c|}{ Basic WaterHammer Program for Upstream Reservoir } & CVA(1) & CVA(2) & CVA(3) & CVA $(4)$ & \multirow{2}{*}{$\frac{\text { CVA(5) }}{0.001}$} & \multirow{2}{*}{$\frac{\operatorname{CVA}(6)}{0.0005}$} & \multirow{2}{*}{$\frac{\operatorname{CVA}(7)}{0.0002}$} \\
\hline $\mathrm{F}$ & .031 & $X \mathrm{~L}$ & 4800 & CVA 0.06 & 0.03 & 0.01 & 0.003 & & & \\
\hline A & 1300 & $\mathrm{~N}$ & 4 & CVA(8) & CVA(9) & CVA(10) & CVA(11) & & & \\
\hline D & 2 & HRES & 100 & 0.0 & 0.0 & 0.0 & 0.0 & & & \\
\hline G & 9.805 & $J P R$ & 1 & & & & & & & \\
\hline \multirow[t]{2}{*}{ DCV } & 5 & TMAX & 40 & & & & & & & \\
\hline & Run & & Clear & Export To Excel & & & & & & \\
\hline \multicolumn{11}{|c|}{ PIEZOMETRIC HEADS AND FLOWS ALONG THE PIPE } \\
\hline & Time & $\mathrm{CV}$ & $X / L=.0$ & $X / L=.25$ & $X / L=.50$ & $X / L=.75$ & $x / L=11.0$ & & & \\
\hline \multirow[t]{12}{*}{ b } & 0 & 0.06 & 100 & 99.33949 & 98.67896 & 98.01845 & 97.35793 & & & \\
\hline & & & 2.621656 & 2.621656 & 2.621656 & 2.621656 & 2.621656 & & & \\
\hline & $0.92307692766 \ldots$ & 0.05446154 & 100 & 99.33948 & 98.67897 & 98.01845 & 104.1346 & & & \\
\hline & & & 2.621656 & 2.621656 & 2.621656 & 2.621656 & 2.461083 & & & \\
\hline & $1.84615385532 \ldots$ & 0.04892308 & 100 & 99.33949 & 98.67896 & 104.7559 & 111.4679 & & & \\
\hline & & & 2.621656 & 2.621656 & 2.621656 & 2.462012 & 2.287322 & & & \\
\hline & $2.76923078298 \ldots$ & 0.04338462 & 100 & 99.33948 & 105.3774 & 112.0495 & 119.4588 & & & \\
\hline & & & 2.621656 & 2.621656 & 2.462936 & 2.289191 & 2.099827 & & & \\
\hline & $3.69230771064 \ldots$ & 0.03784615 & 100 & 105.9992 & 112.6316 & 120.0007 & 128.1027 & & & \\
\hline & & & 2.621656 & 2.463855 & 2.29105 & 2.102627 & 1.896879 & & & \\
\hline & $4.61538463830 \ldots$ & 0.03230769 & 100 & 113.2141 & 120.5431 & 128.6054 & 137.5096 & & & \\
\hline & & & 2.307882 & 2.292899 & 2.105414 & 1.900598 & 1.677688 & & & \\
\hline
\end{tabular}

Figure 6 Results after running the program with velocity of $1300 \mathrm{~m} / \mathrm{s}$ and $\mathrm{f}=.031$ (see fig.8)

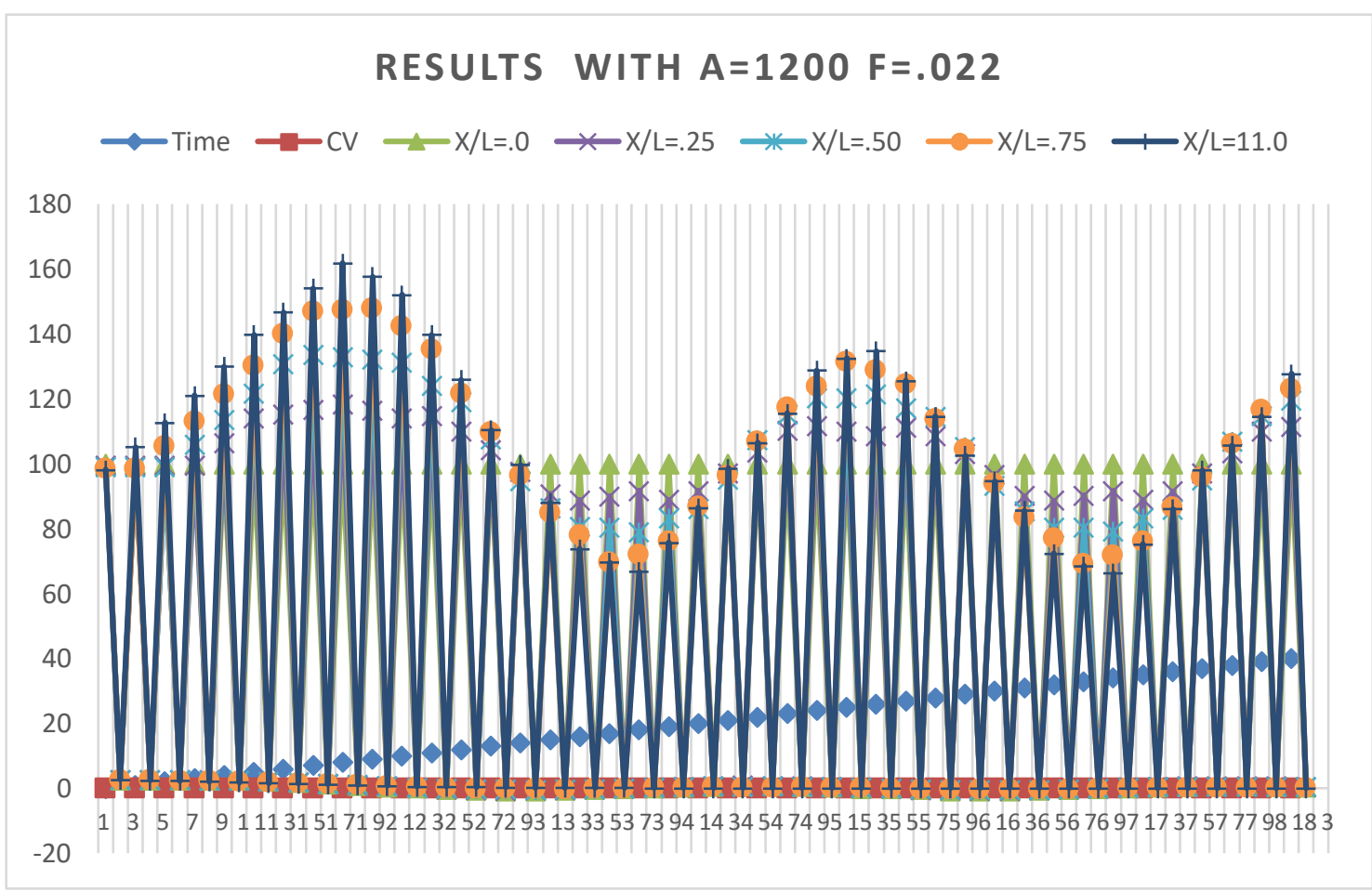

Figure 7 Results after running the program with $\mathrm{a}=1200$ and $\mathrm{f}=0.022$ 
Studying the Effects of Velocity and Coefficient of Friction in Water Hammer Calculations

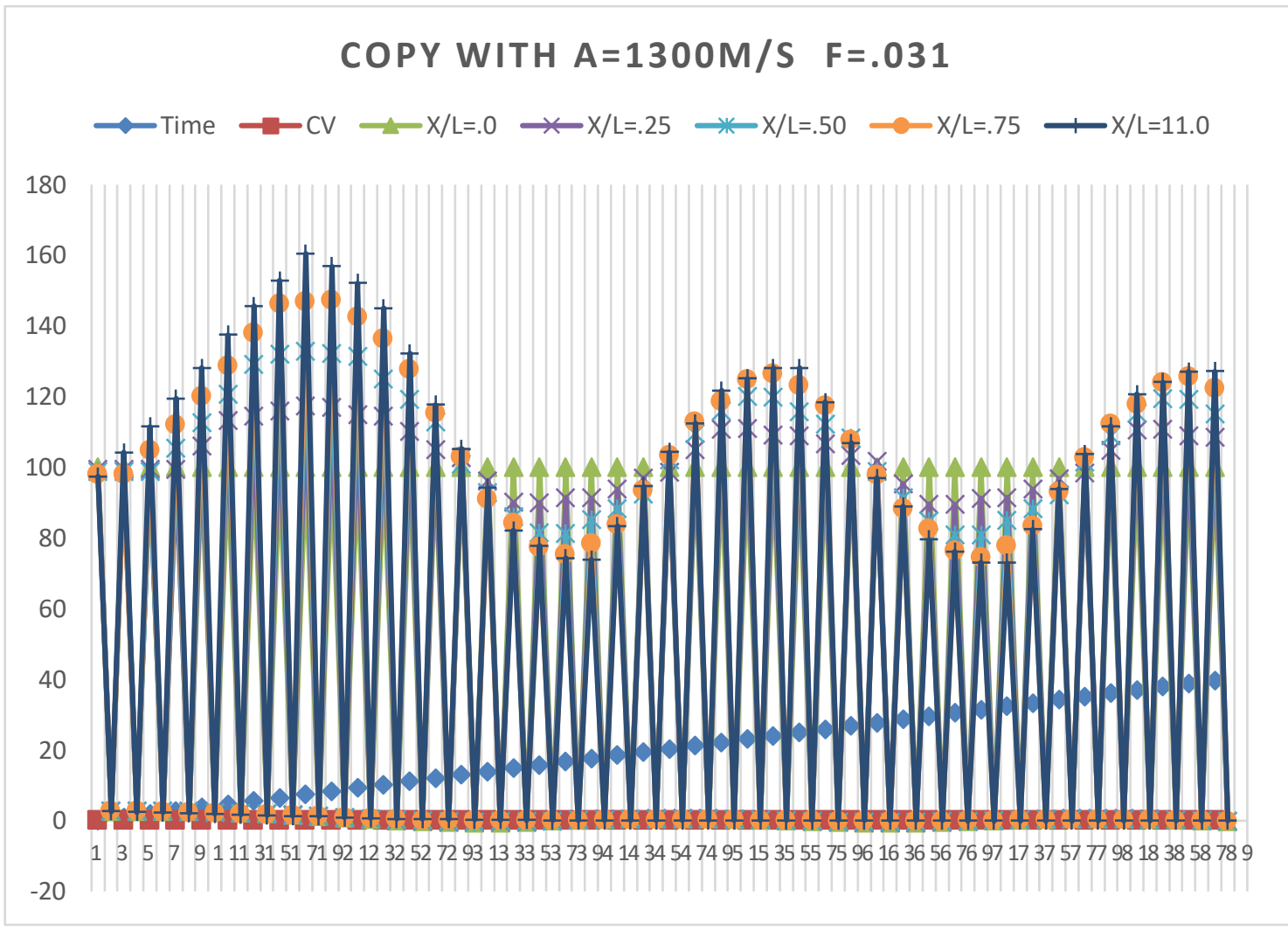

Figure 8 Results after running the program with $\mathrm{a}=1300$ and $\mathrm{f}=0.031$

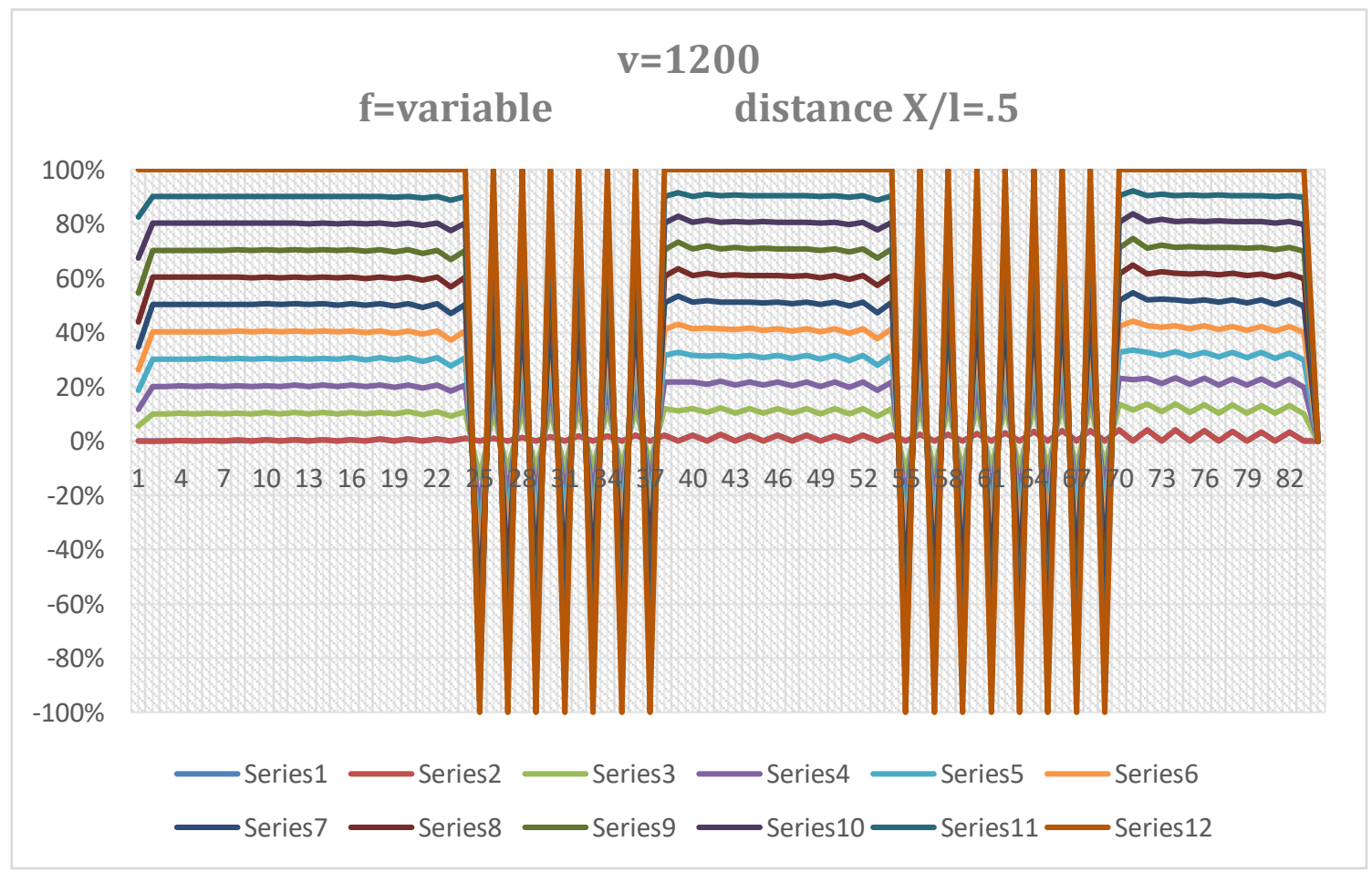

Figure 9 Water hammer results at five values of velocities and 10 values of(f) at $X / L=.05$ 


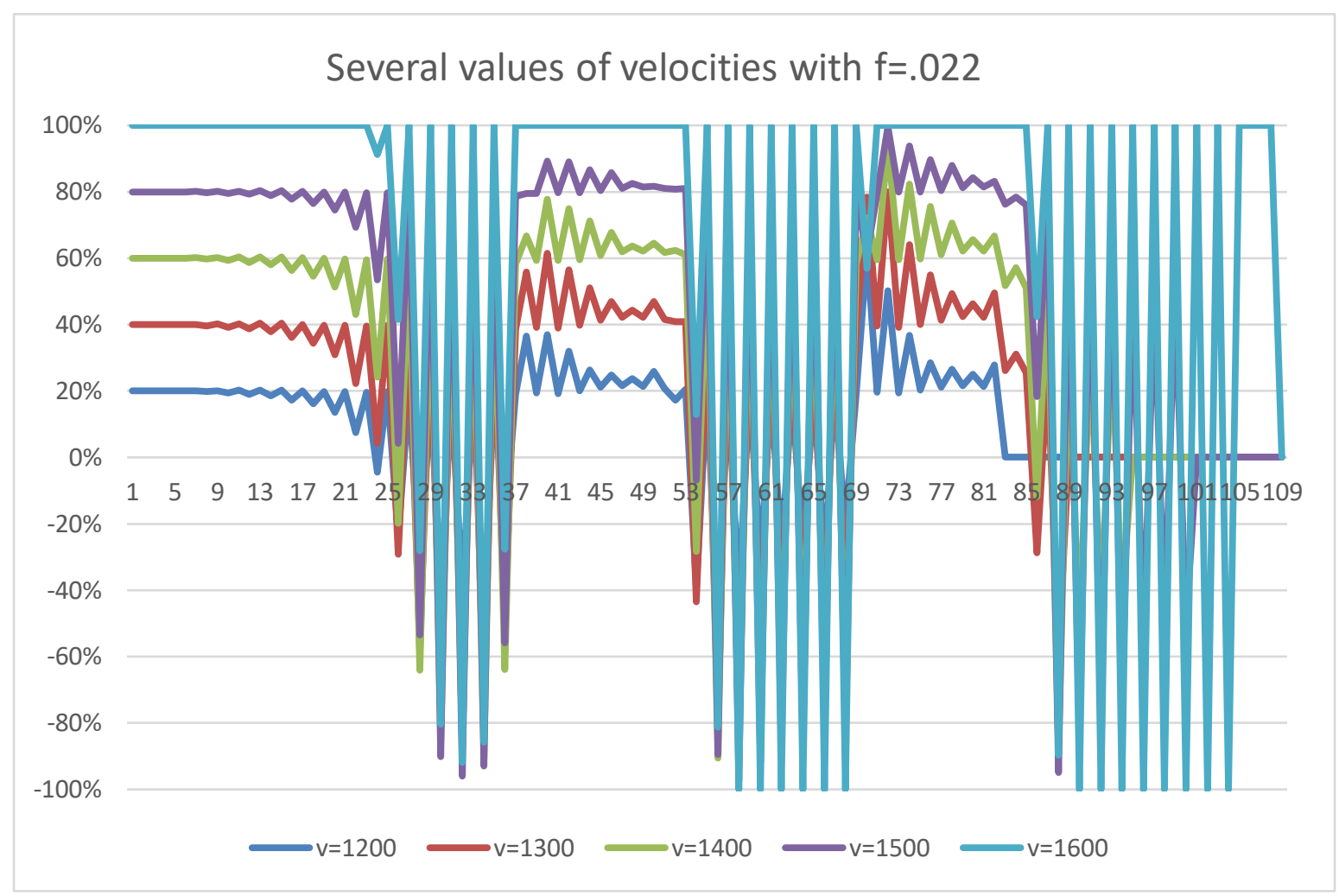

Figure 10 Water hammer results at five values of velocities and $\mathrm{f}=.022$

\section{CONCLUSION}

A system similar to the one shown in figure.1, was studied by a computer program written in visual basic language to calculate water hammer equations ${ }^{[1]}$.

Several data were changed to get more details about water hammed, such us, velocity, coefficient of friction and distance of points on the pipe before the valve. The following notes were gained from 50 tables of data and curves prepared by the program:

- Generally, the curve layout for the results of the water hammer is almost constant, except for a slight difference.

- With the stability of the speed and the change of coefficient of friction, the results of the head at one point, for example, in the middle of the distance between the tank and the valve, are variable and decrease with the high coefficient of friction.

- Values of time in the tables will be decrease with the increasing of velocity, nearly between $91-93 \%$.

- The values of head after running the program, when the valve is initially closed for any speed with constant coefficient of friction is almost constant despite the change of speed and to certain limits, changes in head values start within the limits of the seventh and eighth points of time values and the head values are lower for the higher speed.

\section{REFERENCES}

[1] A M Abdul Razzak. Preparing an educational program to calculate the water hammer with different studies on the phenomenon. International Journal of Civil Engineering and Technology (IJCIET) Volume 10, Issue 01, January 2019, pp. 2978-2989

[2] Michael J. Morgan. Pressure transient characterization test for star-2 propulsion system fuel manifold. In 40th AIAA/ASME/SAE/ASEE Joint Propulsion Conference and Exhibit, 2004. 
[3] Bergant, A., and Simpson, A.R. (1997). Development of a generalized set of pipeline water hammer and column separation equations. Report n. R149, Dept. of Civil, University of Adelaide, Adelaide, Australia.

[4] Joel Carlsson. Water Hammer Phenomenon Analysis using the Method of Characteristics and Direct Measurements using a "stripped" Electromagnetic Flow Meter. August 2016, Division of Nuclear Reactor Technology, Department of Physics Royal Institute of Technology, SE-106 91 Stockholm, Sweden, TRITA-FYS 2016:33, ISSN 0280-316X, ISRN KTH/FYS/ \{16:33SE.

[5] Ali, Rashaa Hussam (water hammer) a project given to building and construction department in technology university, Iraq-Baghdad, 2007-2008.

[6] Zielke mWm (1968) Frequency -Dependent Friction in Transient Pipe Flow. Journal of Basic Engineering ASME, 90(1) 109-115.

[7] Chen, C.-L (1992).” Momentum and Energy Coefficients Based on power-law Velocity profile", Journal of hydraulic Engineering, ASCE, 118(11).1571-1584.

[8] Vardy, A.E., and Brown, J.M.B. (2003)" Transient Turbulent friction in smooth pipe flows" Journal of sound and vibration, 259(5), January, 1011-1036.

[9] Streeter, Victor L \& Wylie, E., Benjamin, (1983) "Fluid Mechanics" First Si Metric Edition, McGraw, Hill Book Company, printed in Singapore. 